\title{
Computing and Information Disciplines Body of Knowledge
}

\author{
Prof. Mohamed M. El Hadi
}

\author{
Sadat Academy for Management Sciences
}

\begin{abstract}
This work presents the already identified computing and information disciplines' body of knowledge e as identified by the leaded and well international and advanced societies and associations in the advanced countries, such as AMC, IEEE-Computer Society, IAS, IRMA, etc. The work identifies separately the body of knowledge for the following disciplines or subject fields: Computer Science, Information Systems, Information Technology, Software Engineering and Information Management. Other related disciplines as Computer Engineering, Information Science, Management, Mathematics, Ergonomics, Cognitive Science, etc. are being excluded from this work. The main five identified disciplines are represented separately; each disciplinary body of knowledge is organized hierarchically into only two levels. The highest level of this hierarchy concerns the main knowledge area within the identified a particular discipline or a subject field. Each main knowledge area is further subdivided into smaller divisions that could be called unites, domains or courses, which represent the identified thematic module within the knowledge area.
\end{abstract}

The computer science discipline contains eighteen main areas some that are derived from the most recent guidelines of computer science of ACM and IEEE-CS, these main areas are interrelated to the other discipline of this work. The information systems discipline covers four main knowledge areas related to general computing, specific information systems, foundational areas, and domain specific topics.
The specific information systems knowledge area has seven main subjects that each of them is more subdivided to further topics. In connection with information technology discipline, it covers (13) main subject areas concerning systems, information and technology. The software engineering discipline as identified by AIS, AMC, IEEE-CS, and Steven Institute of Technology through its project of iSSSEc issued in 2009 have identified ten main subject areas in this discipline. The information management discipline that derives its main subjects from the works of ACM, AIS, IEEE-CS and other professional organizations such as Data Management Association - International (DAMA) and Information Resource Management Association(IRMA). Ten main subject areas as well as other main knowledge areas of information management are being identified for this work.

From the identified body of knowledge of the five selected disciplines, there is interrelationships among the represented topics and fields of study. The third hierarchical level in each disciplines could be identified in a future separate work benefited with ontological work endeavor. In the meantime, the interrelated works as well as the alphabetically representation of topics will be further listed and indicated in later comprehensive separated works.

Keywords: Body of Knowledge, Computer Science, Information Systems, Information Technology, Software Engineering, Information Management, Information Resource Management

\section{Computer Science Body of Knowledge}

Computer Science as a discipline spans a wide range, from its theoretical and algorith- 
mic foundations to cutting-edge developments in robotics, computer vision, intelligent systems, bioinformatics and other exciting areas. The following figure represents computer science. Which covers most of the vertical space between an extreme top and extreme bottom. The extreme top of computer science relates to information systems infrastructure (operating systems, communication programs), while the bottom or down is as far as software enables devices to work efficiently and probably.

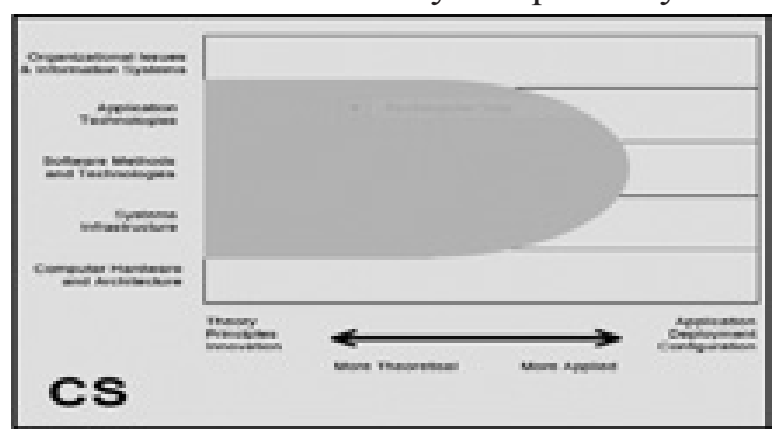

Figure (1) Computer Science Span Areas

(Source: ACM/AIS/IEEE-CS, 2004)

As shown in the above figure the Computer Hardware and Architecture is stricter to the Computer Engineering discipline, while the Software Methods and Technologies are considered the focus for computer science.

The Computer Science body of knowledge is presented as a set of knowledge areas (KAs) organized on topical themes. Each Knowledge Area is further organized into a set of knowledge units or topics. This presented CS Body of knowledge is completely cited from the source works issued by the Association of Computing Machinery and IEEE-Computer Society CS body of knowledge since 2001 and updates up to 2013. (ACM/IEEE-CS, 2013)

1. Algorithms and Complexity (AL)

1.1 Basic Analysis

1.2 Algorithmic Strategies

1.3 Fundamental Data structures and Algorithms

1.4 Basic Automata, Computability, and Complexity
1.5 Advanced Computational Complexity

1.6 Advanced Automata Theory

Computability

1.7 Advanced Data Structures,

Algorithms, and Analysis

2. Architecture and Organization (AR)

2.1 Digital Logic and Digital Systems

2.2 Machine Level Representation of Data

2.3 Assembly Level Machine Organization

2.4 Memory System Organization and

Architecture

2.5 Interfacing and Organization

2.6 Functional Organization

2.7 Multiprocessing and Alternative

Architecture

2.8 Performance Enhancement

3. Computational Science $(\mathrm{CN})$

3.1 Fundamentals

3.2 Modeling and Simulation

3.3 Processing

3.4 Interactive Virtualization

3.5 Data, Information and Knowledge

4. Discrete Structures (DS)

4.1 Sets, Relations and Functions

4.2 Basic Logic

4.3 Proof Techniques

4.4 Basics of Counting

4.5 Graphs and Trees

4.6 Discrete Probability

5. Graphics and Virtualization (GV)

5.1 Fundamental Concepts

5.2 Basic rendering

5.3 Geometric Modeling

5.4 Advanced Modeling

5.5 Computer Animation

5.6 Virtualization

6. Human Computer Interaction (HC)

6.1 Fundamentals

6.2 Designing Interaction

6.3 Programming Interactive Systems

6.4 User-cantered Design and Testing

6.5 Design for Non-Mouse Interfaces

6.6 Collaboration and Communication 
6.7 Statistical Methods for HCI

6.8 Human factors and Security

6.9 Design-Oriented HCI

6.10 Mixed, Augmented and Virtual Reality

7. Information Assurance and Security (IAS)

7.1 Fundamental Concepts

7.2 Network Security

7.3 Cryptography

7.4 Risk Management

7.5 Security Policy and Governance

7.6 Digital Forensics

7.7 Security Architecture on Systems

Administration

7.8 Secure Software Design and Engineering

8. Information Management (IM)

8.1 Information Management Concepts

8.2 Database Systems

8.3 Data Modeling

8.4 Indexing

8.5 Relational Databases

8.6 Query languages

8.7 Transaction Processing

8.8 Distributed Databases

8.9 Physical Database Design

8.10 Data Mining

8.11 Information Storage and Retrieval

8.12 Hypermedia

8.13 Multimedia Systems

9. Intelligent Systems (IS)

9.1 Fundamental Issues

9.2 Basic Search Strategies

9.3 Basic Knowledge Representation and Reasoning

9.4 Basic Machine Learning

9.5 Advanced Search

9.6 Advanced representation and Reasoning

9.7 Reasoning Under Uncertainty

9.8 Agents

9.9 Natural Language Processing

9.10 Advanced Machine Learning

9.11 Robotics

9.12 Perception and Computer Vision

10. Networking and Communication (NC)
10.1 Introduction

10.2 Networked Applications

10.3 Reliable Data Delivery

10.4 Routine and Forwarding

10.5 Local Areas Networks

10.6 Resource Allocation

10.7 Mobility

11. Operating Systems (OS)

11.1 Overview and Operating Systems

11.2 Concurrency

11.3 Scheduling and Dispatching

11.4 Memory Management

11.5 Security and Protection

11.6 Virtual Machines

11.7 Device Management

11.8 File Systems

11.9 Real Time and Embedded Systems

11.10 Fault Tolerance

11.11 Systems Performance Evaluation

12. Platform-Based Development (PBD)

12.1 Introduction

12.2 Web Platforms

12.3 Mobile Platforms

12.4 Industrial Platforms

12.5 Game Platforms

13. Parallel and Distributed Computing (PD)

13.1 Parallelism Fundamentals

13.2 Parallel Decomposition

13.3 Communication and Coordination

13.4 Parallel Algorithms, Analysis and

Programming

13.5 Parallel Architecture

13.6 Parallel Performance

13.7 Distributed Systems

13.8 Formal models and Security

14. Programming Languages (PL)

14.1 Object-Oriented Programming

14.2 Functional Programming

14.3 Event-Driven and Reactive

Programming

14.4 Basic Type systems

14.5 Program Representation

14.6 Language Translation and Execution 
14.7 Syntax Analysis

14.8 Compiler Semantic Analysis

14.9 Code Generation

14.10 Runtime Systems

14.11 Static Analysis

14.12 Advanced Programming Constructs

14.13 Concurrency and Parallelism

14.14 Type Systems

14.15 Formal Semantics

14.16 Language Pragmatics

14.17 Logical Programming

15. Software Development

Fundamentals (SDF)

15.1 Algorithms and Design

15.2 Fundamental Programming Concepts

15.3 Fundamental Data structures

15.4 Development Methods

16. Software Engineering (SE)

16.1 Software processes

16.2 Software Project Management

16.3 Tools and Environments

16.4 Requirement Engineering

16.5 Software Design

16.6 Software Construction

16.7 Software Verification Validation

16.8 Software Evolution

16.9 Formal methods

16.10 Software Reliability

17. Systems Fundamentals (SF)

17.1 Computational Paradigms

17.2 Cross-layer Communications

17.3 State-State Transition-State Machines

17.4 System Support for parallelism

17.5 Performance

17.6 Resource allocation and Scheduling

17.7 Proximity

17.8 Virtualization and Isolation

17.9 Reliability Through Redundancy

18. Social and Professional Practice (SP)

18.1 Social Context

18.2 Analytical Tools

18.3 Professional Ethics

18.4 Intellectual Property
18.5 Privacy and Civil liberties

18.6 Professional Communication

18.7 Sustainability

18.8 History

18.9 Economics of Computing

18.10 Security Policies. Laws and

Computer Crimes

\section{Information Systems Body of Knowledge}

The scope of Information Systems as a field of study encompasses the concepts, principles and processes for one main broad areas of activities within organizations, which is related to the development, operation and evolution of infrastructure and systems for use in organization processes (system development, system operation and system maintenance). The systems that deliver information and communication services in an organization combine both technical components and human operators and users. They capture, store process and communicate, data, information and knowledge. Therefore, Information Systems function in an organization has a broad responsibility to plan, acquire or develop, implement and manage the infrastructure of informationtechnology (computers and communications) data (both internal and external), and enterprisewide information processing systems. Therefore, Information Systems discipline contributes significantly to several domains, including business and government as well. The following figure indicates the close linkage between information systems and business:

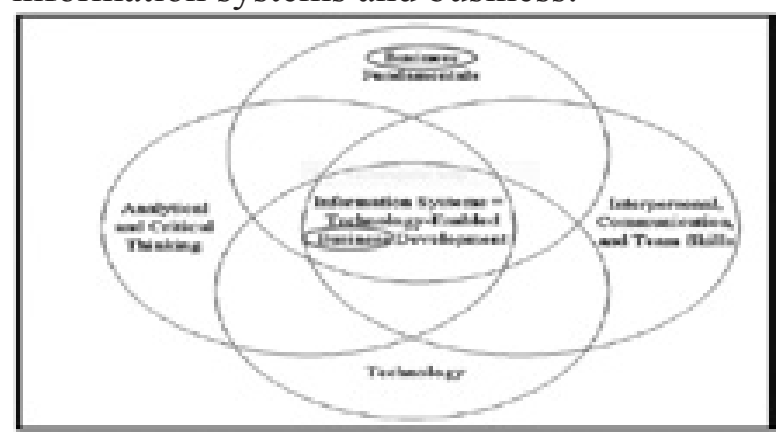

Figure (2) Relationships Between Information Systems and Business

(Source: Gorgone et al (2002) 
From the above figure, we could conclude that information systems as technology-enabled business development is related closely to business fundamentals, communications, technology and analytical thinking.

Hence, IS Body of Knowledge is done in the context of computing ontology project, which has brought together representatives from all computing disciplines to develop a comprehensive concept structure for the entire field of information systems. This IS Body of Knowledge is being devised by both ACM and IAS within their Work entitled "Computing Science Curriculum 2008: An interim Revision of CS 2001" by both ACM and IEE-Computer Society and its revision of IS 2010 (Tapi et al , 2010).

This IS Body of Knowledge is divided into four main categories, which are:

1. General Computing Knowledge Areas

2. Information Systems Specific Areas

3. Foundational Knowledge Areas

4. Domain-Specific Knowledge Areas

Therefore, the overview of Information

Systems Body of Knowledge is presented as the following main four areas:

1. General Computing Knowledge Areas (GC)

1.1 Programming Fundamentals

1.2 Algorithms and Complexity

1.3 Architecture and Organization

1.4 Operating Systems

1.5 Net Centric Computing

1.6 Programming Languages

1.7 Graphic and Visual Computing

1.8 Intelligent Systems

2. Information Systems Specific

Knowledge Areas (IS)

2.1 IS Management and Leadership
2.1.1 Strategy

2.1.2 Management

2.1.3 Sourcing and acquisition

2.1.4 Strategic Alignment

2.1.5 Impact on Organizational Structure and Processes

2.1.6 Planning

2.1.7 Role of IT in Defining and Shaping competition

2.1.8 Managing function

2.1.9 Financing and Evaluating IT

Performance Investments and operations

2.1.10 Acquiring IT Resources and

Capabilities

2.1.11 Using IT Governance Framework

2.1.12 IT Risk management

2.1.13 IS Economics

2.2 IS Data and Information Management

2.2.1 Basic File Processing Systems

2.2.2 Data structures

2.2.3 Data Management approaches

2.2.4 Database Management Systems

2.2.5 Data and Information Modeling at

Conceptual and logical Models

2.2.6 Physical Database implementation

2.2.7 Data retrieval and Manipulation with Database Languages

2.2.8 Data Management and transactional Processing

2.2.9 Distributed databases

2.2.10 Business intelligence and

Decision Support

2.2.11 Security and privacy

2.2.12 Policies and Compliance

2.2.13 Data integrity and Quality

2.2.14 Data and Database Administration

2.3 IS Systems Analysis and Design 
2.3.1 Systems Analysis and design Philosophies and Approaches

2.3.2 Business Process Design and Management

2.3.3 Analysis of Business Requirements

2.3.4 Analysis and Specifications of systems requirements

2.3.5 Configuration and Change Management 2.3.6 Implementing IS Different Approaches

2.3.7 High-Level System Design Issues

2.3.8 Identification of Opportunities for IT-Enabled Organizational Change 2.3.9 Realization of IT-Based Opportunities With Systems Development Projects

\subsubsection{Systems deployment and} implementation

2.3.11 Systems Verification and validation

2.4 IS Project Management

2.4.1 Project Management and fundamentals

2.4.2 Managing Project Teams

2.4.3 Managing Project Communications

2.4.4 Project initiation and Planning

2.4.5 Project Execution and Control

2.4.6 Project closure

2.4.7 Project quality

2.4.8 Project Risk

2.4.9 Project management standards

2.5 IS Enterprise Architecture

2.5.1 Enterprise Architecture framework

2.5.2 Component Architecture

2.5.3 Enterprise Application Service Delivery

2.5.4 System integration

2.5.5 Content Management

2.5.6 Interorganizational Architecture

2.5.7 Processes for Developing

Enterprise Architecture

2.5.8 Architecture Change Management
2.5.9 Implementing Enterprise Architecture

2.5.10 Enterprise Architecture and Management Control

2.6 IS User Experience

2.6.1 Usability Goals and assessment

2.6.2 Design Processes

2.6.3 Interaction Styles

2.6.4 Interaction Devices

2.6.5 Information Search

2.6.6 Information Visualization

2.6.7 User documentation and Online Help

2.6.8 Error Reporting and Recovery

2.7 IS Professional Issues in IS

2.7.1 Social Context of Computing

2.7.2 Legal issues

2.7.3 Ethical Issues

2.7.4 Intellectual Property

2.7.5 Privacy

2.7.6 IS as a Profession

3. Foundational Knowledge Areas (FK)

3.1 Leadership and Communication

3.2 Individual and Organizational Knowledge Work Capabilities

4. Domain-Related Knowledge Areas (DK)

4.1 General Models of the Domain

4.2 Key Specialization Within the Domain

4.3 Evaluation of Performance Within the Domain

Information Technology Body of Knowledge

Information Technology as a discipline concerns two main meanings. In the broadest sense, it is often used to refer to all computing. In the narrowest sense, IT refers to the technology needs of business, government, healthcare, educational institutions and other organizations and agencies. Therefore, IT emphasizes the technology discipline, which started as a grassroots response to practical, 
everyday needs of business and other organizations, since they are dependent on IT in everyday activities. It is recognized that organizational systems must work properly, be secure, and be upgraded, maintained and replaced as appropriate.

The following figure represents IT discipline that focuses on the application, deployment, and configuration needs of organizations and people over a wide spectrum, i.e., from organizational information systems, to application technologies and down to systems infrastructure. IT role overlap with information systems, but IT personnel have a special focus on satisfying human needs and arise from computing technology.

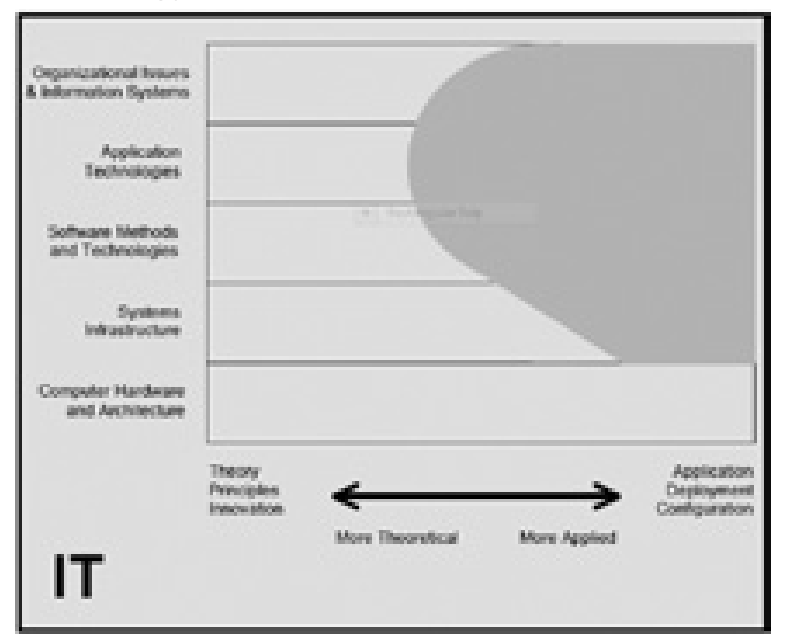

Figure (3) Information Technology Span Areas (Source: ACM/AIS/IEEE-CS, 2004)

The above figure shows IT discipline as shaded on the right side, which focuses nowadays on developing Web-enabled digital technologies that organizations and individuals use for a mix of information purposes.

The following listing of IT body of Knowledge shows the main knowledge areas and the main units, domains or courses in each identified knowledge area. The listing contains thirteen IT knowledge areas as identified by the ACM and IEEE-Computer Society in their work on Computing Curricula Information
Technology issued in 2008.

1. Information Technology Fundamentals (ITF)

1.1 Pervasive Themes in IT

1.2 History of IT

1.3 Application Domains

2. Human Computer Interaction (HCI)

2.1 Human Factors

2.2 Aspects of Application Domains

2.3 Human-Centered Evaluation

2.4 Developing Effective Interfaces

2.5 Accessibility

2.6 Emerging Technologies

2.7 Human-Centered Software Development

3. Information Assurance and Security (IAS)

3.1 Security Mechanisms

3.2 IAS Operational Issues

3.3 Policy

3.4 Attacks

3.5 Security Domains

3.6 Forensics

3.7 Information States

3.8 Security Services

3.9 Threat Analysis Model

3.10 Vulnerabilities

4. Information Management (IM)

4.1 Database Query Languages

4.2 Data Organization Architecture

4.3 Data Modeling

4.4 Managing the Database Environment

4.5 Special-Purpose Databases

5. Integrative Programming and Technologies (IPT)

5.1 Intersystem Communications

5.2 Data Mapping and Exchange

5.3 Integrative Coding

5.4 Scripting Technologies 
neering discipline is completely different in character from other engineering disciplines, due the both the intangible nature of software and to the discontinuous nature of software operations.

As the discipline of Software Engineering natured, the scope of its challenge become clearer. In addition to its computer science foundations, software engineering also involves human processes that are by their nature are harder to formulize than the logical abstraction of computer science.

Software engineering covers, nowadays, a wide range of needs in large project software expertise. Its main goal is to develop systematic models and reliable techniques for production of high-quality software and these concerns extend all the way from theory and principles to daily practice as shown in the following figure:

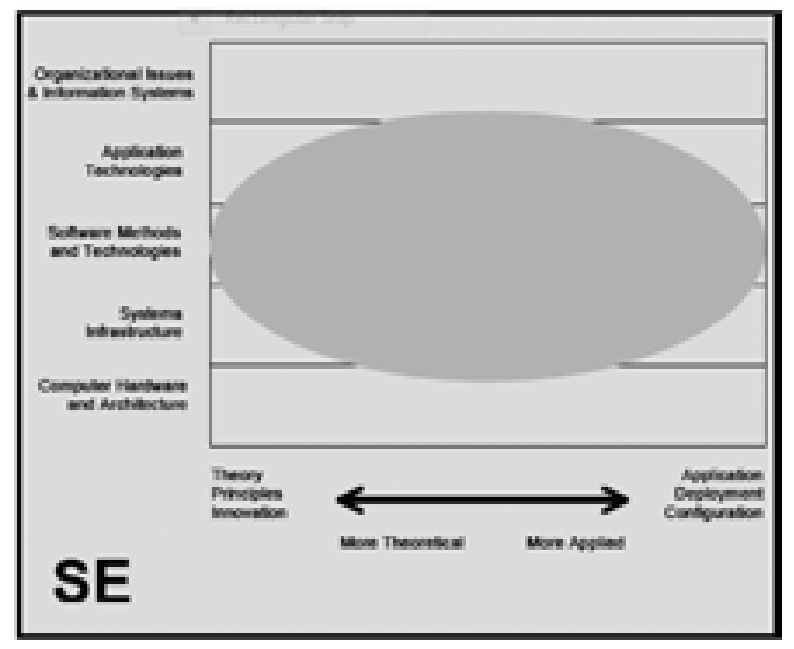

Figure (4) Software Engineering Span Areas (Source: ACM/AIS/IEEE-CS, 2004)

The above figure shows that software engineering discipline seeks to integrate the principles of mathematics and computer science with the engineering practices developed from tangible, physical artifacts.

The Software Engineering Body of Knowledge is considered, as a milestone in reaching a broad agreement on the content of the soft- ware engineering field or discipline, therefore as with the other computing and information disciplines is not an end process. The existing SE Body of Knowledge is originally based on the work of IEEE-Computer's Guide to Software Engineering Body of Knowledge that was issued in 2004 version, which is considered the basic for this discipline. [IEE-CS/ ACM Task Force..., August 2004; Bourque and Dupuis, R. eds., 2004\& Stevens Institute of Technology, 2009]

1. Software Requirements (SR)

1.1 Software Requirements Fundamentals

1.2 Requirement Process

1.3 Requirements Elicitation

1.4 Requirements Analysis

1.5 Requirements Specification

1.6 Requirement Validation

1.7 Practice Considerations

2. Software Design (SD)

2.1 Software Design Fundamentals

2.2 Key Issues in Software Design

2.3 Software Structure and Architecture

2.4 Software Design Quality Analysis and Evaluation

\subsection{Software Design Notations}

2.6 Software Design and Methodologies

3. Software Construction (SC)

3.1 Software Construction Fundamentals

3.2 Managing Construction

3.3 Practical Considerations

4. Software Testing (ST)

1.1 Software Testing Fundamentals

1.2 Test Levels

1.3 Test Techniques

1.4 Test Related Measures

1.5 Test Process

2. Software Maintenance (SM)

2.1 Software Maintenance Fundamentals

2.2 Key Issues in Software Maintenance

2.2.1 Technical Issues

2.2.2 Management Issues

2.2.3 Maintenance cost Estimation 
2.3 Maintenance Process

2.4 Techniques for Maintenance

3. Software Configuration Management (SCM)

3.1 Management of Software Configuration Management

\subsection{Software Configuration Identification}

3.3 Software Configuration Control

3.4 Software Configuration Status Accounting

3.5 Software Configuration Auditing

3.6 Release Management and Delivery

4. Software Engineering Management (SEM)

4.1 Initiation and Scope Definition

4.2 Software Project Management

4.3 Software Project Enactment

4.4 Review and evaluation

\subsection{Closure}

4.6 Software Engineering Measurement

5. Software Engineering Process (SEP)

5.1 Process Implementation and Change

5.2 Process definition

5.3 Process Assessment

5.4 Product and Process Measurement

6. Software Engineering Tools and Methods (SET)

6.1 Software Engineering Tools

6.2 Software Engineering Methods

7. Software Quality (SQ)

7.1 Software Quality Fundamentals

7.2 Software Quality Management Processes 10.3Practical Considerations

\section{Information Management Body of Knowledge}

Information Management as a discipline is primary concerned with capturing, digitization, representation, optimization, transformation and presentation of information and algorithms for efficient and effective access and updating of stored information, data modeling and abstraction, physical file storage techniques. Therefore, this area of knowledge requires the ability to develop conceptual and physical data models, determine what information management methods and techniques are appropriate for a given problem, and the ability to select and implement an appropriate solution that addresses relevant design concerns including scalability, accessibility and usability of data, information and knowledge.

Information Management is the development, execution and supervision of plans, policies, programs and practices that control, protect, deliver and enhance the value of data and information assets in any organization. Therefore, information management is an important function for all kind and levels of organizations in any sector of the society. IM is a shared responsibility between business data stewards and information management professionals. IM is a new and maturity profession that is considered the central focal point for all the computing discipliners. Scientific associations and organizations such as Association for Computing Machinery (ACM) and IEEEComputer Society (IEEE-CS/ACM, 2001 \& ACM/IEEE-CS, 2013) have underlined the discipline of Information Management to include the following topics:

1. Information Management Principles

2. Information Models and systems

3. Data Modeling

4. Database Systems

5. Indexing

6. Relational Data

7. bases

8. Query Languages

9. Transaction Processing

10. Distributed Databases

11. Physical Database Design 


\section{Data Mining}

13. Information storage and Retrieval

14. Hypertext and Hypermedia

15. Multimedia information systems

While, the Information Resource Management Association (IRMA) and Data Management Association-International (DAMA) are among the numerous scientific organizations that are being concerned with formulating the body of knowledge for data/information management. The data/information management functions as drawn by DAMA, International Foundation in 2007 have been stated in the following figure:

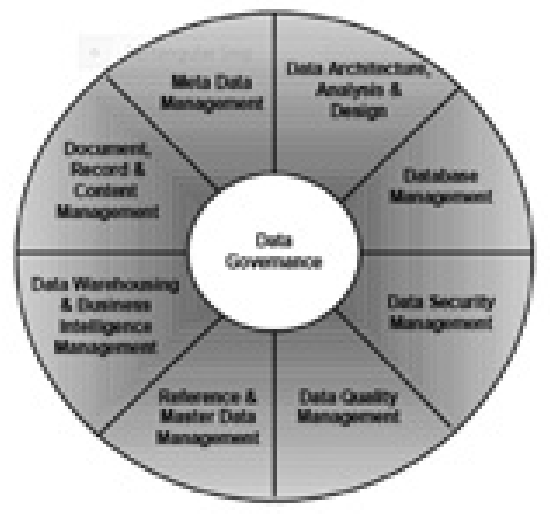

Figure (5)Data/Information Management Functions [Source: Mosley, Mark ed. 2007]

This main model of the data management body of knowledge areas has been updated in December 20013 as in the following figure:

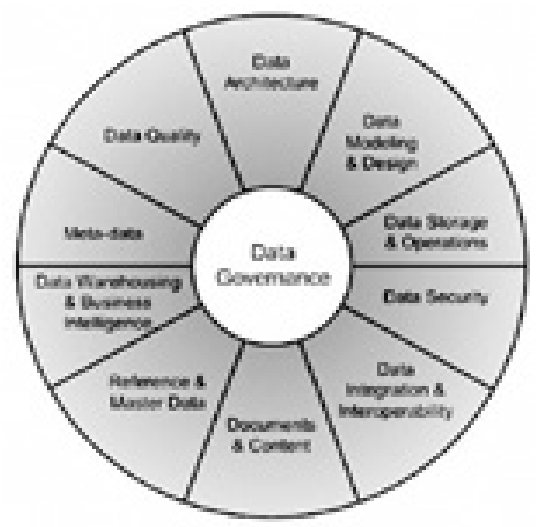

Figure (6) Data/Information Management Functions (Source: http;//www.dama.org)
It is noticed in the 2013, that the data model context of the main knowledge areas the addition of new areas, such as Data Modeling and Design; Data Storage and Operations; and Data Integration and Interoperability, also the areas of professional ethics and data in cloud are being added to Data Governance;as well as the rearrangement of the other topics within the model.

In this connection, according to the Data Management Association (DAMA), data resource management is the development and operation of architectures, plans, policies and procedures that properly manage the full life cycle needs of an enterprise or organization. Therefore, data resource management may be thought of as a managerial activity that applies information system and other data management tools to task of managing an organization's data resources to meet its main business needs, and the information to be provided to the shareholders. From the perspective of data design, it refers to the development and maintenance of data models to facilitate data sharing between different systems, particularly in an organization context. In addition, data resource management is concerned with data quality and compatibility between data models. From this prospective, data are just considered as facts, in systems data are generally represented as content in a field. Data become information when they are structured to provide context and meaning for any organization's function. The management of data are generally focuses on the defining of data element and how it is structured, stored and moved, while management of information is more concerned with security, accuracy, completeness and timeliness of multiple pieces of data.

Anyway, the function scope related to earlier created functions of the data management 
body of knowledge in 2007 was stated as in the following figure:

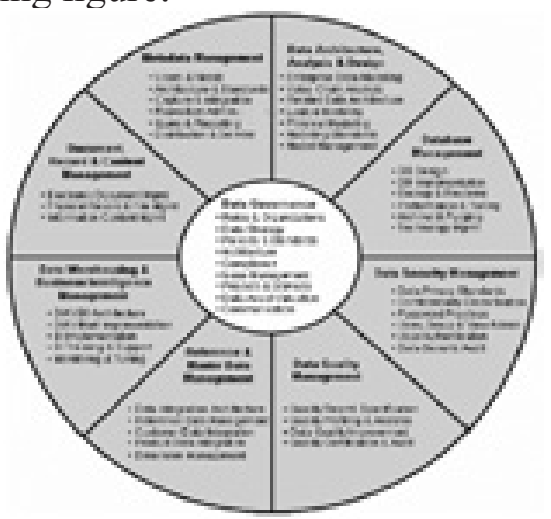

Figure (6) Data/Information Function Scope

(Source: Mosely, Mark, ed. 2007)

These main topics regarding Data/Information knowledge areasare being endorsed by both the Data Governance Institute [http:// www.datagovernce.com/adg_dat_gpvernance_defintion.html] and the American Institute of CIPAs [http://aicpa.org/IMTA] and indicated as follows:

1. Data/Information Governance

1.1 Data/Information Management Planning

1.2 Data/Information Supervision and Control

2. Data/Information Architecture, Analysis and Design:

2.1 Enterprise Data/Information Architecture

2.2 Data/Information Modeling and Specification

3. Data/Information Development

3.1 Systems development life Cycle (SDLC)

3.2 Data/information requirement Analysis and Design

3.3 Data/information Implementation and updating

4. Database Management Systems

4.1 Database Development

4.2 Database Production Support
4.3 Data Technology Management

5. Data/Information Security Management

5.1 Information Privacy and Security Policies

5.2 Privacy and Security Standards

6. Reference and Master Data/Information Management

6.1 Data integration architecture

6.2 Reference Data Management

6.3 Customers and Products Data integration

6.4 Dimension Management

7. Data Warehousing, Mining and Business Intelligence Management

7.1 Data warehousing

7.2 Data Mining

7.3 Business Intelligence

8. Document, Record and Content Management

8.1 Electronic Documents and Records Management

8.2 E-Archiving

8.3 Content Management

9. Metadata Management

9.1 Metadata standards

9.2 Metadata Requirements

9.3 Metadata Repository Management

9.4 Metadata Distribution and Delivery

10. Data/Information Quality Management

10.1 Quality Management Planning

10.2 Quality Management Control activities

10.3 Quality Management Techniques

While the Information Resource Management Association (IRMA) and Data Administration Managers Association (DAMA) [Cohen, Eli ed. (2000] had discussed an IRMA Model curriculum and its relationships Between Business Functions, Information Concepts and Information Technology in the following figure: 


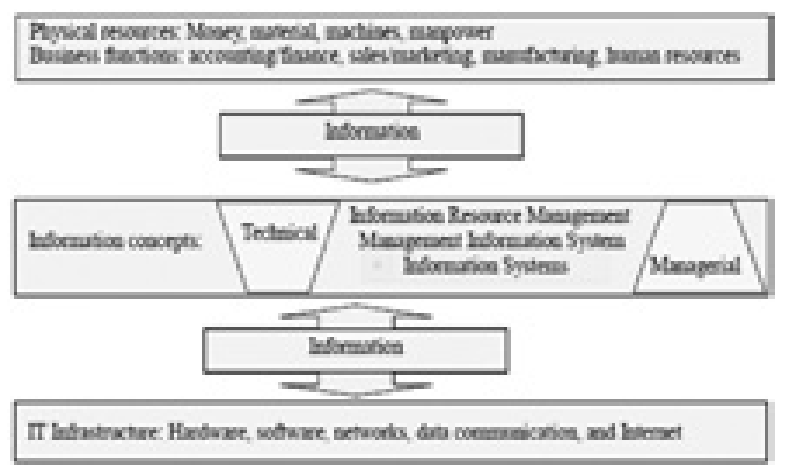

Figure (7) Relationshipsbetween Business Functions,

Information and Information Technology (Source: Cohen, 2000)

The information management curriculum Model of IRMA lists the main subject areas and their subdivisions as follows:

1. Information Resource Management Principles

1.1 Information Management

1.2 Types of Information

1.3 Value of Information

1.4 Information Processing Techniques

1.5 Information Processing Personnel and Users

1.6 Information Users and Types of Information

1.7 Information Systems Structures

1.8 Information Delivery Technologies

2. Information Systems Technologies

2.1 Components of Information Systems Technologies

2.2 Role of Information ystems in Organizations

2.3 Systems Professionals and Information in Organizations

2.4 Information Systems Processing Methods in Organizations

2.5 Structure of Information Systems in Organizations
2.6 Organizational Ethics and Security Information Systems

3. Algorithm Concepts and Information Management

3.1 Algorithm Planning and Information Systems

3.2 Algorithm Processing and Information Systems

3.3 Algorithm Validation Concepts and Output Errors

3.4 Algorithm Technology and Data Management

4. Data Resource Structures and Administration

4.1 Data Resources and Information

4.2 Database concepts and Application

4.3 Application of Data Administration

4.4 Strategic Information Systems Planning

5. Data Warehousing, Data Mining and Decision Support Systems

5.1 Decision Support Systems

5.2 Data Warehousing

5.3 Data Mining

6. Information Resource Management Design and Implementation

6.1 Information Management and Information Systems

6.2 Systems Analysis and Information Systems

6.3 Systems Definition of Information Systems

6.4 System Design of Information Systems

6.5 Systems Implementation of Information Systems

6.6 Systems Maintenance and Management of Information Systems

6.7 Information Resource Management and Behavior 
7. Communication Technology and Information Management

7.1 Telecommunications and Information

7.2 Communication Technology

7.3 Communication Design

7.4 Communication Controls

7.5 Communication Systems Planning and Development

8. Global Information Management

8.1 Global Information Resource Management

8.2 Information Technology and Global Marketing

8.3 Information Technology and International financial Services

8.4 Information Technology and International Accounting

8.5 Information Technology and Global Operations

8.6 Information Technology and Research and Development

8.7 Information Technology and Global Human resources

9. Executive Information Systems Management

9.1 Executive Decision Making

9.2 Executive direction of Information Systems

9.3 Strategic Application of Information Systems

9.4 Executive Information Systems and Control of Information

The IRMA's information resource management curriculum model, emphasis the information systems in organizations that concerns the information resource contained in them. Therefore, any information management body of knowledge is to be deduced from all of the above endeavors as well as the knowledge management domains that have been emerged because of information processing.

\section{Conclusion}

This work indicates that computing and information are broad disciplines that cross the boundaries of several other knowledge domains as mathematics, physics, science, engineering, psychology, etc. It covers the body of knowledge of only five designated disciplines (computer science, information systems, information technology, software engineering and data/information management). These five disciplines are being briefly discussed and indicating the main knowledge areas in each of them according the works of the pioneering professional and scientific organizations and association in each discipline. From the listing of the knowledge areas in each discipline, it could be noticed that they are interrelated to each other. The computer science is related to data structure of the data management and responsible for constructing programs regarding the software engineering to suit the information systems required for the organizational function. This means that any specialization within each of these disciplines should be inter-linked with the other computing and information disciplines.

It is to notice that, since the beginning of information age, businesses need all types of data on their business activities. With each data created, when business transaction is made, need data is created. With these data new direction is needed that focuses on managing data as a critical resource on the organization to directly support its business activities. The data resource must be managed with the same intensity and formality that other critical resources are managed. Processing the data and information needs constructing the programs that formulate the required software that is the focal point in information systems. All these 
aspects require technological infrastructure to be ready for any organization, such as computer hardware, software and telecommunications that constitute the information technology functions for any organizations.

Therefore, any organization must emphasize the information aspect of computer science, software engineering, information systems and information technology, to determine the data and information needed to support the business, and then use appropriate technology to build and maintain high-quality information systems that provide the needed support to the decision makers.

\section{References:}

1. ACM/AIS/IEEE-CS. Joint Task Force for Computing Curricula (2004). Computing Curricula 2004: Overview Report Including a Guide to Undergraduate Degree Programs in Computing [http://www.acm.org/education/ curricula]

2. ACM/IEE-CS. The Joint Task Force on Computing Curricula (2013). Computer Science Curricula 2013Final Report [http://www. acm.org/education/curricula]

3. American Institute of CIPAs (2013). [http://aicpa.org/IMTA]

4. Bourque, P. and Dupuis, E. eds. (2004). SWEBOK Guide to the Software Engineering Body of Knowledge. New York: Computer Society Press

5. Cohen, Eli ed. Curriculum Model 2000 of Information Resource Management Association and Data administration Managers Association. [http://gise.org/Irma-dama-2000.pdf]

6. Data Governance Institute. An Overview of Data Management [http://www.datagovernance.com/adg_data_governance_definition. html]

7. Data Administration managers Associa- tion (August 2011). DAMA Data Management Body of Knowledge (DAMA DMBOK).1st ed. 2009.

8. Gorgone, John et al (2002). IS 2002 Model Curriculum and Guidelines for Undergraduate Programs in Information Systems, by ACM, AIs and AITP [http://www.acm.org/education/ curricula]

9. Henderson, Deborah (Jan. 2010). DAMA Guide to Data Management Body of Knowledge [http://www.dama.org]

10. IEEE-CS/ACM Joint Task Force on Computing Curricula (December 2001]. Computing curricula 2001: Computer Science [http:// info.acm.org/education]

11. IEEE-CS/ACM Joint Force on Computing Curricula (December 2004). Software Engineering 2004: Curriculum Guidelines for Undergraduate Degree Programs in Software Engineering [http://www.acm.org/education/ curricula]

12. Mosley, Mark ed. 9Nov. 2007). Data Management Body of Knowledge as Drawn by DAMA international Foundation[http:// www.dama.org]\

13. Smith, Loretta M. (20100. Data Management Professional Certification Overview \{http://www.iccp.org]2009 (GSWE) Curriculum Guidelines for Graduate Degree Programs in Software Engineering. V. 1.0

14. Stevens Institute of Technology iSSSEc project (2009). Graduate Software Engineering

15. Topi, Heikki et al (2010). IS 2010 Curriculum Guidelines for Undergraduate Degree Programs in Information Systems by Association for Computing Machinery(ACM) and Association for Information Systems (AIS) [http://www.aisnet.org] and [http://www.acm. org/education/curricula] 